Mônica Elinor Alves Gama 1 Janaina de Sousa Barbosa 1 Benedito Pires 2

Anna Karenine Braúna Cunha 1 Alecídia Ri bei ro Freitas 1 Ionar Rezende Ribeiro 1 Jackson Maurício Lopes Costa 1

\section{Avaliação do nível de conhecimento que populações residentes em áreas endêmicas têm sobre leishmaniose visceral, Estado do Maranhão, Brasil}

\author{
Evaluation of the level of knowledge about \\ visceral leishmaniasis in endemics areas \\ of Maranhão, Brazil
}

\footnotetext{
1 Núcleo de Patologia Tropical e Medicina Social, Departamento de Patologia, Universidade Federal do Maranhão. Praça Madre Deus 02, São Luís, MA 65025-560, Brasil. 2 Fundação Nacional de Saúde. Rua lo de Janeiro s/no São Luis, MA 65040-450, Brasil.
}

Abstract A prospective study was performed to identify knowl edge concerning visceral lei shmaniasis (VL) in endemic areas of Maranhão, amongst the rural population of the Codó township and in a peripheral urban area (an old settlement, Maracanã, on the outskirts of the city of São Luís, and Vila Nova/Bom Viver, Paço do Lumiar township). A total of 283 persons were intervi ewed, including 53 from Maracanã, 103 from Vila Nova/Bom Viver, and 127 from Codó. The sites presented favorable conditions for the devel opment and maintenance of VL. Some $93.8 \%$ of those intervi ewed had heard of kala-azar. In Maracanã, 50.9\% referred to sandflies as responsible for the transmission of $\mathrm{VL}$, while $87.2 \%$ knew that dogs are the main link in the epidemiological cycle of the disease. Some 77.8\% of those interviewed did not know how to control the disease. As regards manifestati ons of the disease, they largely associated it with fever, anemia, weight loss, and an enlarged abdomen. Only five individuals knew that Glucantime ${ }^{\circledR}$ is used to treat VL. We conclude that knowledge is poor with regard to all aspects of VL in both the rural and peripheral urban area.

Key words Visceral Leishmaniasis; Awareness; Epidemiology

Resumo Estudo prospectivo visando identificar e comparar que conhecimentos bási cos relativos à lei shmaniose visceral (LV) têm as populações com característi cas distintas, resi dentes em áreas periurbanas (Maracanã - instalação e ocorrência de casos de LV antigas; Vila Nova/Bom Viver instalação e ocorrência recentes) e rural, Municípi o de Codó - instalação anti ga e ocorrência recentes. No período compreendido entreagosto de 1996 a janei ro de 1997, apli cou-se questionário com perguntas abertas e fechadas, sendo abordados aspectos referentes à epidemiologia, prevenção, clínica eterapêutica. A população de estudo foi formada pelos casos de LV registrados pela FNS/MA e seus vizinhos. Foram entrevistados os resi dentes de 283 casas: 53 do Maracanã; 103, em Vila Nova/Bom Viver; 127, em Codó. Foi referido ambiente favorável para o desenvolvimento e manutenção da doença. Do total dos entrevistados, 93,8\%, percentual significativo, ouviram falar de LV, por meio de fontes não ofi ciais. No Maracanã, 50,9\% referiram transmissão pelo mosquito; $87,2 \%$ reconheciam o envolvimento do cão na cadeia epi demiológica da doença. Os entrevistados estão cientes da gravi dade do mal, sendo capazes de identificar casos su speitos, humano ou canino. Medidas de controle são desconheci das por $77,8 \%$. Sete pessoas sabiam que o Glucantime ${ }^{\circledR}$ é usado no tratamento da LV. Concluiu-se que o nível de conhecimento sobre LV foi baixo, principalmente em relação à prevenção eà terapêutica, situação semel hantes nas três áreas. Palavras-chave LeishmanioseVisceral; Conhecimentos; Epidemiologia 


\section{Introdução}

A leishmaniose visceral (LV), ou calazar, encontra-se amplamente distribuída no mundo, principalmente em regiões tropicais e subtropicais da Ásia, Oriente Médio, África, América Central e América do Sul. Embora seja uma doença predominantemente rural, os registros têm revelado um processo de urbanização da LV no Brasil, fato já previsto por Alencar, desde a década de 50. Atualmente, este comportamento tem-se mantido, especialmente nas cidades de São Luís/MA, Teresina/PI, Fortaleza/CE, Aracajú/SE e Rio de Janeiro/RJ (Alencar, 1983; Nascimento et al., 1996).

No Estado do Maranhão, desde 1988, observa-se franca expansão da doença, predominantemente nas áreas periurbanas dos municípios localizados na Il ha de São Luís (São Luís, Paço do Lumiar e São José de Ribamar) (Alvim et al., 1986; Costa et al., 1995).

As transformações ambientais decorrentes da intensa migração por pressões econômicas e sociais, a pauperização da população em razão da má distribuição de renda, a crescente urbanização e o êxodo rural provocaram o agravamento dessa endemia, com o aparecimento de novos focos no Brasil (MS, 1996). Esses fatores têm contribuido para o aumento da morbidade e mortalidade infantil e para a redução na capaci dade de trabal ho de adultos em plena fase produtiva, prejudicando assim o desenvolvimento econômico das regiões atingi das e gerando grave problema de saúde pública (Gonçalves et al., 1986; Vieira, 1987).

Nas doenças endêmicas, o conhecimento de sua epidemiologia traz relevantes contribuições, pois, com base nesses conhecimentos, pode-se chegar a um eventual controle das mesmas. Os conceitos, atitudes e crendices da população acerca de determinada endemia constituem-se, também, em fatores importantes para o seu controle (Netto et al., 1985).

Em geral, o comportamento das comunidades sujeitas a endemias não é considerado. A literatura tem mostrado que as populações residentes em zonas rurais e nas periferias das cidades de alguns países das Américas são carentes de informações acerca das doenças que as afligem, como observaram Netto et al. (1985) e Vázquez et al. (1991), respectivamente, nas regiões de Três Braços/ BA (Brasil) e Bajo San Juan (Colômbia), em trabalhos sobre leishmaniose tegumentar americana (LTA).

Para desenvolver estratégias contra uma enfermidade, deve-se conhecer o comportamento do homem diante da mesma, pois, assim, tendo por base conceitos adequados, po- de-se orientá-lo sobre como reduzir o risco de adquiri-la. Esteso (1984), em estudo realizado na província de Córdoba (Argentina), mostrou a interferência do nível de conhecimento da comunidade na incidência da doença de Chagas; durante o período em que foram devidamente orientados sobre diversos aspectos da endemia, houve queda na incidência, tendo-se registrado aumento progressivo logo após a suspensão da divulgação.

Assim, justifica-se a realização deste estudo, cujo intuito é identificar que conhecimentos básicos referentes à LV têm as populações com características distintas, residentes em áreas endêmicas, e que também visa fornecer subsídios para trabal hos voltados à educação da comunidade e ao controle da doença.

\section{Material e métodos}

Realizou-se estudo prospectivo, no período de agosto de 1996 a janeiro de 1997, em três áreas endêmicas para LV, no Estado do Maranhão, com incidência anual de, em média, 4,3 casos por mil crianças. As localidades selecionadas para o estudo foram Vila Nova/Vila Bom Viver, bairro do Maracanã e zona rural do Município de Codó. Optou-se por uma área com ocorrência antiga de casos de LV, como o bairro do Maracanã, que desde a década de 80 tem sido acompanhado pela Fundação Nacional de Saúde (FNS/MA), e, também, áreas de ocorrência recente, Vila Nova/Bom Viver e Codó, onde os registros mostram casos a partir de 1993.

O bairro do Maracanã, fundado há 122 anos, localiza-se na área periurbana do Município de São Luís (capital do Estado), apresentando características rurais, com um total de 430 prédios, em sua maioria sítios e chácaras, distribuídos ao longo de locais arborizados com plantações frutíferas e capinzal para pecuária bovina. Sua população, de aproximadamente 1.640 habitantes, tem como principal atividade econômica o cultivo de produtos hortifrutigranjei ros. Dista aproximadamente $18 \mathrm{~km}$ do centro de São Luís, ligando-se a esta cidade por rodovia asfaltada.

Vila Nova eVila Bom Viver localizam-se na periferia do Município de Paço do Lumiar. Situam-se ao longo da rodovia que liga o município da Raposa à capital (a 28km). Trata-se de uma região de invasão recente (cerca de nove anos de instalação), com aproximadamente 3.990 habitantes. A atividade econômica desenvolvida pelos moradores baseia-se na pesca.

Fundado há cem anos, o Município de Codó localiza-se na região ecológica do cerrado, 
no leste do estado do Maranhão, distante $291 \mathrm{~km}$ de São Luís; com uma população de 114.070 habitantes, apresenta características rurais, sendo a agricultura e a pecuária as principais atividades econômicas.

O trabalho de campo junto às comunidades foi realizado por uma equipe de profissionais da área de saúde, pertencentes à Universidade Federal do Maranhão (UFMA) e à Fundação Nacional da Saúde (FNS-MA), devidamente treinados quanto à utilização do material e com relativo conhecimento das áreas. Por meio de entrevista individual com o responsável pela residência no momento da visita, procedeuse aplicação de uma ficha-questionário composta de perguntas abertas e fechadas, das quais constavam dados relativos a identificação, condições de moradia, características epidemiológicas e conhecimentos sobre aspectos epidemiológicos, preventivos, clínicos e terapêuticos da LV.

Utilizando-se o critério de vigilância epidemiológica adotado pela FNS/ MA, com base no registro de um caso humano, mapearam-se as localidades, e, partindo-se da casa-problema (aquela com caso registrado de LV no período do estudo), incluiu-se uma área de aproximadamente $200 \mathrm{~m}$ para a direita e $200 \mathrm{~m}$ para a esquerda, observando-se a distribuição das casas por área, visando abranger os vizinhos próximos à casa-problema. A população de estudo foi composta pela casa-problema e pelos vizinhos da mesma, sendo entrevistados 53 indivíduos na localidade do Maracanã; 103, em
Vila Nova/ Bom Viver, e 127, na zona rural de Codó.

Procedeu-se análise estatística dos dados, utilizando-se o teste do Qui-Quadrado para estabelecer diferenças significativas $(p \leq 0,05)$, do programa Epi Info (versão 6.0, 1994, Center for Disease Control/Epidemiology Program Office; Atlanta, Georgia).

\section{Resultados}

Nas três localidades estudadas, foram entrevistados 283 indivíduos. Na Tabela 1, podem-se observar as condições de moradia dos entrevistados. No bairro do Maracanã, constataramse casas com melhor estrutura física em relação a Vila Nova/Bom Viver e Codó ( $p=0,0000$ ), predominando cobertura de telha, parede de alvenaria e piso de cimento. Em ambas as localidades da I lha de São Luís, 100,0\% dos entrevistados relataram não dispor de coleta pública de lixo e apenas 3,8\% possuíam água encanada em suas casas; já em Codó, 33,8\% possuem coleta pública de lixo e 77,2\% recebem água encanada. Em 92,2\% das casas entrevistadas não há banheiros.

A Tabela 2 traz detalhes em relação às características epidemiológicas das populações. Pode-se observar que 146 pessoas $(51,5 \%)$ possuem cães no domicílio, na maioria saudáveis. Os entrevistados que referiram cães doentes citaram sinais sugestivos de LV: queda de pêlos, animal 'pirento' (com feridas) e emagrecido.

\section{Tabela 1}

Condições de moradia das populações estudadas, segundo estrutura física.

\begin{tabular}{|c|c|c|c|c|c|c|}
\hline \multirow[t]{2}{*}{ Estrutura física } & \multicolumn{2}{|c|}{ Maracanã } & \multicolumn{2}{|c|}{ Vila Nova/Bom Viver } & \multicolumn{2}{|c|}{ Codó } \\
\hline & $\mathrm{n}$ & $\%$ & $n$ & $\%$ & $\mathrm{n}$ & $\%$ \\
\hline \multicolumn{7}{|c|}{ Tipo de cobertura } \\
\hline Telha & 49 & 92,5 & 33 & 32,1 & 45 & 35,4 \\
\hline Palha & 4 & 7,5 & 67 & 65,0 & 80 & 63,0 \\
\hline Outros & - & - & 3 & 2,9 & 2 & 1,6 \\
\hline \multicolumn{7}{|l|}{ Tipo de parede } \\
\hline Alvenaria & 29 & 54,7 & 7 & 6,8 & 16 & 12,6 \\
\hline Taipa & 24 & 45,3 & 90 & 87,4 & 106 & 83,5 \\
\hline Outros & - & - & 6 & 5,9 & 5 & 3,9 \\
\hline \multicolumn{7}{|l|}{ Tipo de piso } \\
\hline Cerâmica & 18 & 34,0 & 1 & 1,0 & 7 & 5,5 \\
\hline Cimento & 22 & 41,5 & 11 & 10,7 & 21 & 16,5 \\
\hline Terra batida & 13 & 24,5 & 87 & 84,5 & 96 & 75,6 \\
\hline Outros & - & - & 4 & 3,8 & 3 & 2,4 \\
\hline
\end{tabular}


Tabela 2

Características epidemiológicas das populações estudadas.

\begin{tabular}{|c|c|c|c|c|c|c|}
\hline \multirow[t]{2}{*}{ Características epidemiológicas } & \multicolumn{2}{|c|}{ Maracanã } & \multicolumn{2}{|c|}{ Vila Nova/Bom Viver } & \multicolumn{2}{|c|}{ Codó } \\
\hline & $\mathrm{n}$ & $\%$ & $\mathrm{n}$ & $\%$ & $n$ & $\%$ \\
\hline Presença de cão no domicílio & 26 & 49,1 & 38 & 36,9 & 48 & 37,8 \\
\hline Cão doente no domicílio & - & - & 03 & 2,9 & 07 & 5,5 \\
\hline Mortes recentes de animais & 05 & 9,4 & 13 & 12,6 & 20 & 15,7 \\
\hline Cão no peridomicílio & 50 & 94,3 & 81 & 78,6 & 121 & 95,3 \\
\hline Mucura nas proximidades & 27 & 50,9 & 05 & 4,8 & 32 & 25,2 \\
\hline Raposa nas proximidades & 02 & 3,8 & 04 & 3,9 & 26 & 20,5 \\
\hline Presença de mosquito & 26 & 49,1 & 56 & 54,4 & 101 & 79,5 \\
\hline História familiar de LV & 11 & 20,8 & 16 & 15,5 & 21 & 16,5 \\
\hline História de LV nas proximidades & 29 & 54,7 & 56 & 54,4 & 81 & 63,8 \\
\hline
\end{tabular}

Houve relato de mortes recentes de cães em $12,5 \%$ das casas, $79,7 \%$ das quais ocorreram há menos de um ano. No Maracanã, 94,3\% dos entrevistados relataram presença de cães no peridomicílio, sendo 54,0\% animais doentes. Na localidade Vila Nova/ Bom Viver, dos $78,6 \%$ que citaram cães nas imediações, 28,4\% afirmaram que os mesmos encontravam-se doentes e, em Codó, de $95,3 \%$, apenas $13,4 \%$ referiram animais suspeitos de LV.

A referência à presença de animais silvestres envolvidos na epidemiologia da doença mostrou diferenças significativas. No Maracanã e em Codó, foi relatada a presença de didelfídeos (mucuras) nas proximidades em percentuais significativamente mais elevados que em Vila Nova/Bom Viver ( $p=0,0000)$. A raposa foi citada em percentuais bem menores nas localidades periurbanas em relação à zona rural de Codó, com diferença estatisticamente significante $(p=0,000065)$.

Em relação a presença de mosquitos, 49,1\% dos entrevistados no Maracanã relatam a presença dos mesmos no domicílio ou peridomicílio; em Codó, o percentual é de 79,5\%. No bairro Maracanã, $62,3 \%$ das casas entrevistadas possuem criação de animais nas proximidades, $28,3 \%$ localizam-se perto de rios, mangues ou lagos e 3,8\% estão próximas a matas; em Vila Nova/Bom Viver, esses percentuais são menores, $43,7 \%, 17,5 \%$ e $2,9 \%$, respectivamente. Em Codó, $37,8 \%$ residem próximo a matas e $23,6 \%$ têm criação de animais.

Nas três localidades, os percentuais foram aproximados em relação à história de LV em familiares (média $=17,6 \%$ ) e nas proximidades (média =57,8\%).

A idade dos 283 entrevistados variou de 14 a 89 anos, sendo encontrados os maiores percentuais na faixa etária de 21 a quarenta anos.
Com referência ao grau de instrução, os dados mostram que $48,5 \%$ dos indivíduos possuíam o primeiro grau incompleto. O bairro Maracanã apresentou o menor percentual de analfabetismo (7,5\%) e Codó, o maior, com $47,2 \%$ de analfabetos, diferença estatisticamente significativa $(p=0,0000)$. Nas áreas periurbanas, a profissão do lar foi a mais citada (média $=56 \%$ ). Em Codó, 36,2\% eram lavradores e 29,1\%, domésticas.

Os entrevistados foram questionados a respeito da doença nos seus mais variados aspectos. Conforme mostra a Tabela 3, no bairro do Maracanã, 96,4\% dos entrevistados já tinham ouvido falar sobre calazar, $34,0 \%$ dos quais receberam essa informação de amigos e 34,1\%, de fontes oficiais de informação (programas de televisão, agentes de saúde, folhetos informativos e palestras na escola). Na localidade de Vila Nova/ Bom Viver, dos 93,2\% que ouviram falar na doença, 36,9\% citam que também receberam essa informação de amigos e 45,6\%, de agentes de saúde, médicos, programas de TV ou rádio, folhetos informativos ou na escola. Em Codó, 92,1\% referem ter ouvido falar de LV, $44,1 \%$ de fontes oficiais e $16,5 \%$, de amigos ( $\mathrm{Fi}$ gura 1). Percebe-se diferença estatisticamente significativa $(p=0,0000)$ quanto à fonte de informação entre a área pertencente à capital do Estado e as demais, localizadas em outros municípios.

Quando perguntados se conheciam o calazar por outros nomes, 95,0\% dos entrevistados desconheciam outras denominações, sendo citados como sinônimos doença do cão, leishmaniose e barriga d'água.

Em relação ao modo de transmissão da doença, 50,9\% dos entrevistados do Maracanã responderam que o mosquito seria o responsável, diferença estatisticamente significante em relação às demais localidades ( $p=0,0001)$. Os 
Tabela 3

Principais respostas às questões abordadas sobre aspectos gerais do calazar.

\begin{tabular}{|c|c|c|c|c|c|c|}
\hline \multirow[t]{2}{*}{ Questões abordadas } & \multicolumn{2}{|c|}{ Maracanã } & \multicolumn{2}{|c|}{ VilaNova/BomViver } & \multicolumn{2}{|c|}{ Codó } \\
\hline & $\mathrm{n}$ & $\%$ & $\mathrm{n}$ & $\%$ & $\mathrm{n}$ & $\%$ \\
\hline \multicolumn{7}{|l|}{ Já ouviu falar sobre calazar? } \\
\hline $\operatorname{Sim}$ & 51 & 96,4 & 96 & 93,2 & 117 & 92,1 \\
\hline Não & 2 & 3,8 & 7 & 6,8 & 10 & 7,9 \\
\hline \multicolumn{7}{|l|}{ Outros nomes para o calazar } \\
\hline Não sabe & 52 & 98,1 & 100 & 97,1 & 124 & 97,6 \\
\hline Doença do cão & 1 & 1,8 & 1 & 0,9 & 1 & 0,8 \\
\hline Leishmaniose & - & - & 1 & 0,9 & 2 & 1,6 \\
\hline Barriga d'água & - & - & 1 & 0,9 & - & - \\
\hline \multicolumn{7}{|l|}{ Como é transmitido o calazar? } \\
\hline Mosquito & 27 & 50,9 & 27 & 26,2 & 25 & 19,7 \\
\hline Cão doente & 5 & 9,8 & 10 & 10,4 & 13 & 10,2 \\
\hline Não sabe & 21 & 39,3 & 66 & 63,4 & 89 & 70,1 \\
\hline \multicolumn{7}{|l|}{ Nomes do mosquito transmissor } \\
\hline Não sabe & 52 & 98,1 & 99 & 96,1 & 127 & 100,0 \\
\hline Arrupio & 1 & 1,8 & 3 & 2,9 & - & - \\
\hline Cangalhinha & - & - & 1 & 0,9 & - & - \\
\hline \multicolumn{7}{|c|}{ Animal que também apresenta calazar } \\
\hline Cão & 46 & 86,8 & 90 & 87,4 & 111 & 87,4 \\
\hline Mucura & 2 & 3,8 & 1 & 0,9 & 1 & 0,8 \\
\hline Raposa & - & - & 2 & 1,9 & - & - \\
\hline Não sabe & 5 & 9,4 & 10 & 9,8 & 15 & 11,8 \\
\hline \multicolumn{7}{|c|}{ Época de maior ocorrência do calazar } \\
\hline Não sabe & 27 & 50,9 & 40 & 38,8 & 47 & 37,0 \\
\hline Chuva & 20 & 37,7 & 48 & 46,6 & 69 & 54,3 \\
\hline Seca & 6 & 11,3 & 15 & 14,6 & 11 & 8,7 \\
\hline \multicolumn{7}{|l|}{ Como prevenir calazar? } \\
\hline Não sabe & 38 & 71,6 & 76 & 73,7 & 112 & 88,2 \\
\hline Evitar criadouros & 9 & 17,0 & 6 & 5,8 & 4 & 3,1 \\
\hline Evitar cães doentes & 6 & 11,3 & 20 & 19,4 & 3 & 2,4 \\
\hline Evitar o doente com LV & - & - & 1 & 0,9 & 1 & 0,8 \\
\hline \multicolumn{7}{|l|}{ Atitude diante de um caso suspeito? } \\
\hline Levaria ao hospital/posto & 50 & 94,3 & 97 & 94,2 & 122 & 96,1 \\
\hline Procuraria agente de saúde & 1 & 1,9 & 5 & 4,9 & - & - \\
\hline Não sabe & 2 & 3,8 & 1 & 0,98 & 5 & 3,9 \\
\hline \multicolumn{7}{|l|}{ o que usaria para tratar o calazar? } \\
\hline $\mathrm{N}$ ão usaria nada & 38 & 71,7 & 54 & 52,4 & 42 & 33,1 \\
\hline Sintomático/Medicação caseira & 5 & 9,4 & 8 & 7,8 & 6 & 4,7 \\
\hline $\mathrm{N}$ ão sabe & 10 & 18,8 & 41 & 39,8 & 79 & 62,2 \\
\hline \multicolumn{7}{|c|}{ Que medicamento é usado no calazar? } \\
\hline Não sabe & 47 & 88,7 & 93 & 90,3 & 114 & 89,8 \\
\hline Glucantime ${ }^{\circledR}$ & 1 & 1,9 & 2 & 1,9 & 4 & 3,1 \\
\hline Injeção & 5 & 9,4 & 8 & 7,8 & 9 & 7,1 \\
\hline
\end{tabular}

continua 
Tabela 3 (continuação)

Principais respostas às questões abordadas sobre aspectos gerais do calazar.

\begin{tabular}{|c|c|c|c|c|c|c|}
\hline \multirow[t]{2}{*}{ Questões abordadas } & \multicolumn{2}{|c|}{ Maracanã } & \multicolumn{2}{|c|}{ VilaNova/BomViver } & \multicolumn{2}{|c|}{ Codó } \\
\hline & $\mathrm{n}$ & $\%$ & $n$ & $\%$ & $\mathrm{n}$ & $\%$ \\
\hline \multicolumn{7}{|l|}{ Conhece Glucantime ${ }^{\circledR}$ ? } \\
\hline Sim & 4 & 7,5 & 6 & 5,8 & 8 & 6,3 \\
\hline Não & 49 & 92,5 & 97 & 94,2 & 119 & 93,7 \\
\hline \multicolumn{7}{|c|}{ Para que é usado o Glucantime ${ }^{\circledR}$ ? } \\
\hline Não sabe & 49 & 92,5 & 97 & 94,2 & 119 & 93,7 \\
\hline Para tratamento do calazar & 4 & 7,5 & 3 & 2,9 & 8 & 6,3 \\
\hline Para tratamento da LTA & - & - & 2 & 1,9 & - & - \\
\hline \multicolumn{7}{|l|}{ Q uanto custa o Glucantime ${ }^{\circledR}$ ? } \\
\hline $\mathrm{N}$ ão sabe & 53 & 100,0 & 102 & 99,1 & 127 & 100,0 \\
\hline Aproximadamente três reais & - & - & 1 & 0,9 & - & - \\
\hline
\end{tabular}

nomes comumente dados ao mosquito transmissor da LV foram pouco citados, apenas quatro pessoas citaram 'arrupio' e uma pessoa, 'cangalhinha'. Em média, 87,1\% dos entrevistados referiram que o cão pode ser acometido pela doença e apenas quatro pessoas citaram a mucura. Somente um indivíduo da localidade de Vila Nova/Bom Viver referiu o acometimento da raposa.

Para prevenção da doença, $77,8 \%$ das pessoas entrevistadas não sabem que medidas tomariam. As medidas preventivas adotadas seriam: evitar cães doentes, criadouros de mosquitos ou o doente com LV. Um total de $64,7 \%$ dos entrevistados não utilizam as medidas que citaram.

Quando interrogados sobre a conduta que tomariam em face de um caso suspeito de LV, $94,8 \%$ responderam que levariam a pessoa ao hospital ou ao posto de saúde mais próximo. Quanto ao que usariam para tratar um doente de LV, 71,7\% dos entrevistados do Maracanã, $52,4 \%$ de Vila Nova/Bom Viver e 33,1\% de Codó não usariam nada, somente o que fosse orientado por médico.

Apenas sete entrevistados citaram o Glucantime ${ }^{\circledR}$ como medicação usada para o tratamento de LV, porém, na pergunta induzida “Você conhece o Glucantime ${ }^{\circledR}$ ?" esse número aumentou (18 pessoas). Quinze entrevistados referiram o uso do Glucantime ${ }^{\circledR}$ para tratamento de calazar e dois reconheceram seu uso no tratamento de leishmaniose tegumentar americana (LTA). Somente uma pessoa de Vila Nova/ Bom Viver respondeu à questão do custo do Glucantime ${ }^{\circledR}$, referindo valor aproximado de três reais por ampola.
As pessoas também foram questionadas sobresinais e/ ou sintomas que poderiam ser apresentados por um indivíduo com LV. Os entrevistados das três localidades relataram, em geral, associações de sintomas. Na localidade do Maracanã, 49,0\% citaram aumento do diâmetro abdominal (barriga grande, baço inchado); 43,4\%, febre; $41,5 \%$, anemia, e percentual igual citou emagrecimento. Em Vila Nova/Bom Viver, emagrecimento foi relatado por $44,7 \%$; aumento do diâmetro abdominal, por 45,6\%; anemia, por $37,7 \%$, e febre, por 29,1\%. Finalmente, em Codó, aumento do diâmetro abdominal foi citado por $64,6 \%$ dos entrevistados; emagrecimento, por $51,2 \%$; febre, por $17,3 \%$, e anemia, por $12,6 \%$.

Quanto às características apresentadas por um cão com calazar, no Maracanã, citaram-se queda de pêlos por 75,5\%; cão 'pirento' (com feridas, coceiras, sarnento), por 58,5\%, e emagrecimento, por 49\%. Em Vila Nova/ Bom Viver, os percentuais variaram: cão 'pirento' foi mencionado por 70,9\%; queda de pêlos, por $51,7 \%$, e emagrecimento, por $40,8 \%$. Em Codó, emagrecimento foi referido por $52,7 \%$ dos entrevistados; queda de pêlos, por $51,2 \%$, e cão 'pirento', por $26,8 \%$.

\section{Discussão}

Consi derando-se que a LV encontra-se entre as doenças de maior ocorrência em zonas rurais e, nos últimos anos, em áreas periurbanas do nordeste brasileiro, realizou-se o presente estudo em localidades do Estado do Maranhão que possuem características de endemicidade para a doença (Fonte: FNS/ MA). 
Figura 1

Distribuição percentual das populações estudadas, segundo fonte de informação.

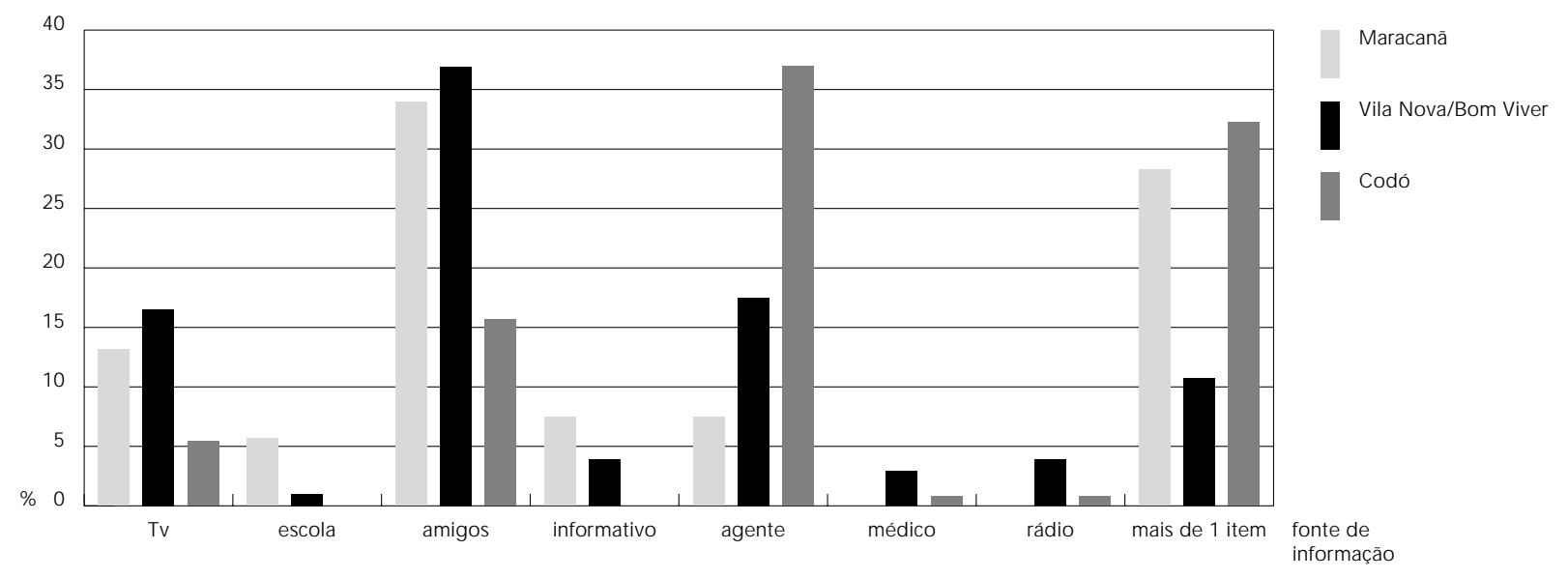

Sabendo-se que a comunidade do Maracanã encontra-se instalada há mais de cem anos e pertence à capital do Estado, justifica-se sua melhor estrutura física; no entanto, por localizar-se em área periurbana, observa-se precariedade no saneamento básico. Vila Nova/Bom Viver e Codó mostram características de moradia compatíveis com citações da literatura que afirmam ser a LV mais incidente em áreas de baixo nível sócio-econômico, com casas de taipa, cobertas de palha e piso de terra batida (Rocha et al., 1991; MS, 1996).

Pode-se sugerir que a presença de cães, no domicílio e peridomicílio dessas localidades permanece como importante elo na cadeia de transmissão da LV, uma vez que a enzootia canina precede a ocorrência de casos humanos (Genaro et al., 1995; MS, 1996). Vale ressaltar que Nascimento (1996), em trabalho realizado na Ilha de São Luís, propôs que a presença do cão no domicílio não seria fator de risco associado à ocorrência de LV, fazendo-se necessária outra população animal como reservatório.

As características ecológicas distintas apresentadas por cada localidade podem explicar a diferença estatisticamente significante no tocante à referência a animais silvestres. $\mathrm{O}$ bairro do Maracanã e o Município de Codó guardam características rurais, com grande número de árvores frutíferas, o que favorece a presença da mucura (didelfídeo), animal que se alimenta também de frutas e adquire facilmente hábitos peridomiciliares.

A referência à presença de didelfídeos no peridomicilio merece destaque, pois foi obser- vado, na Colômbia, que este animal é importante reservatório de Trypanosoma cruzi e Leishmania chagasi (Travi et al., 1994). No Brasil, foi encontrado, no Estado da Bahia, um exemplar de didelfídeo infectado com Leishmania chagasi entre 54 animais examinados (Sherlok et al., 1984). Levando-se em consideração a distribuição geográfica das espécies de didelfídeos (Didel phis marsupiallis e/ ou Didel phis al bi ventris) nas Américas e sua grande capacidade de domiciliação, deve-se pensar em futuros estudos sobre a possibilidade de os mesmos funcionarem como reservatórios primários da Lei shmania chagasi em nosso meio.

A raposa, animal silvestre também envolvido no ciclo da LV, foi citada em percentuais menores nas duas áreas periurbanas. Essas localidades apresentam pequenas áreas de mata de capoeira (áreas devastadas, com mata em recuperação), e, sendo animais exclusivamente carnívoros, as raposas não encontram ambiente favorável a sua sobrevivência na Il ha de São Luís. A existência de áreas com mata preservada em Codó explica a presença de raposas nas proximidades das casas.

Sendo a LV transmitida através da picada de mosquitos (flebotomíneos), as pessoas foram questionadas em relação à presença dos mesmos no domicílio e peridomicílio, sem preocupação com a diferenciação de espécies. Observando-se que a domiciliação do vetor Lutzomyia Iongi pal pis poderia ser estimulada por fatores como a urbanização, a destruição de ecótopos silvestres, a oferta de fontes alimentares, humanas e animais, a arborização 
abundante em quintais, o acúmulo de lixo ou presença de criadouros e abrigos de animais, constata-se um ambiente favorável nas três localidades para os vetores da doença (Costa et al., 1995).

A localização das casas próximas à criação de animais, lagos, rios ou matas é característica relevante na epidemiologia do calazar ( $M$ arzochi et al., 1986). Considerando-se que as localidades do Maracanã e Codó apresentam características de zona rural, observa-se condições ambientais mais propícias à doença. Nas três localidades, no que se refere à história de LV em familiares ou nas proximidades, os percentuais foram aproximados, confirmando os registros da FNS/ MA, que mostram uma incidência semelhante de LV nas áreas em estudo.

Uma vez que as entrevistas foram realizadas com a pessoa de maior idade que se encontrasse no domicílio no momento da abordagem, observa-se uma grande variedade em relação às características dos entrevistados. Tendo-se em vista que a localidade do Maracanã apresenta melhores condições, tanto em relação a instalações próprias, quanto às instalações coletivas (escolas), e, também, por pertencer à capital do Estado, justifica-se o menor índice de analfabetismo encontrado. As profissões citadas foram variadas, destacando-se as atividades do lar e os aposentados, já que as entrevistas foram realizadas em horário de trabalho.

Percebe-se que os entrevistados já tinham recebido alguma informação sobre a doença. Merece destaque o considerável percentual de indivíduos que receberam a informação de fontes informais, o que sugere que o programa de controle da LV do Ministério da Saúde (MS, 1996), que tem como um dos objetivos específicos "manter a população informada e orientada sobre a doença, reservando espaço para sua participação ativa no desenvol vimento das ações de controle", não está sendo satisfatório nessas áreas.

Em Codó, percebeu-se diferença estatisticamente significativa em relação à fonte de informação: 37,0\% receberam-na de agentes de saúde, fato compreensível, uma vez que o Programa de Municipalização da Saúde foi implantado, principalmente, em zona rural, e tanto o município, quanto a FNS/ MA investiram em recursos humanos, visando ao trabalho do agente de saúde junto à população.

Observa-se, de um modo geral, que, nos países em desenvolvimento, todas as ações dirigidas para controlar determinado problema de saúde em uma população afetada ou exposta, sempre deixam de lado a educação popular como medida sanitária concreta, constituindo- se em um ponto débil que, na maioria das vezes, pode levar ao fracasso dos programas de controle, como ocorreu com a doença de Chagas, em países como Brasil e Argentina (Esteso, 1984; García-Zapata, 1990).

A grande maioria dos entrevistados (média =95,0\%) reconheceu a doença somente como calazar, porém uma pessoa referiu 'barriga dágua' como sinônimo de LV; acredita-se quea mesma tenha tido contato anterior com a esquistossomose mansônica forma hepato-esplênica descompensada. Duas pessoas citaram 'doença do cão', refletindo seu conhecimento sobre o envolvimento do mesmo na LV.

O reconhecimento da transmissão da LV pelo mosquito foi estatisticamente diferente entre as localidades, explicado pelo fato de o Maracanã ser área de ocorrência mais antiga de LV. Observa-se em estudos semelhantes sobre outras endemias que as populações, em geral, não detêm conhecimento sobre o modo de transmissão daquelas (Magalhães et al., 1990; García-Zapata, 1990). Em Mambaí (GO), área endêmica para doença de Chagas, quando iniciaram as ações de combate aos triatomíneos, a população local mostrou desconhecimento sobre como poderia participar no controle da doença, por não saber o modo de transmissão da mesma (García-Zapata, 1990).

Apenas cinco pessoas entrevistadas referiram conhecer o mosquito transmissor com outros nomes, 'arrupio' e 'cangalhinha', o que denota a baixa difusão dos conhecimentos sobre a doença dentro da comunidade dessas áreas que apresentam uma incidência significativa de LV (MS, 1996).

Observa-se que a população das três áreas estudadas é capaz de identificar apenas o cão como envolvido na cadeia epidemiológica da doença, pois somente seis pessoas referiram o envolvimento de outros animais, como a mucura ou a raposa.

O período de chuvas, que em nosso Estado compreende os meses de janeiro a junho, foi citado como de maior incidência de LV, concordante com a literatura que refere na época chuvosa um maior número de casos (Rocha et al., 1991).

Apesar do razoável conhecimento sobre os aspectos epidemiológicos da doença, observase que a maioria desconhece que medidas preventivas podem ser adotadas para o controle do calazar. A interferência do conhecimento popular na prevenção de endemias é mostrado por Esteso (1984), em trabal ho sobre a doença de Chagas, onde se observa que programas preventivos promovem queda na incidência da doença. 
A conduta que $94,8 \%$ dos entrevistados tomariam diante de um caso de LV, que seria procurar auxílio médico, demonstra que, mesmo desconhecendo al guns aspectos da doença, as pessoas reconhecem sua gravidade, uma vez que só tomariam qualquer atitude após orientação por profissional de saúde.

Quanto ao tratamento da doença, percebese total desconhecimento sobre a droga utilizada na LV, independente de ter-se história de calazar na família ou nas proximidades, demonstrando que a oportunidade que se tem, ao conduzir um caso, de orientar os familiares mais próximos não está sendo aproveitada; aspecto diferente foi visto na região de Três Braços/ BA, onde a população reconheceu o Glucantime ${ }^{\circledR}$ como medicação específica para o tratamento da LTA (Netto et al., 1985).

No que diz respeito às características apresentadas pelo doente com LV, percebe-se que os entrevistados detêm certo conhecimento acerca do quadro clínico da doença, o que também é verdadeiro com relação aos sinais apresentados por um cão com calazar. Isso mostra que as localidades têm contato importante com a doença, condizente com os dados de elevada incidência da mesma nas áreas (FNS/MA). Diante do relativo conhecimento que os indivíduos demonstraram sobre o aspecto clínico da LV, tanto no cão, quanto no homem, pode-se pensar na participação efetiva da comunidade no controle do calazar, uma vez que, mostrando-se capazes de identificar um caso pelos principais sinais e/ ou sintomas, a comunidade poderia referir os suspeitos de LV mais precocemente aos serviços de saúde.

\section{Conclusões e recomendações}

A análise e discussão dos dados coletados no presente estudo permite-nos concluir que:

- As três áreas estudadas apresentam ambiente favorável para o desenvolvimento e manutenção da leishmaniose visceral, uma vez que foram referidas a presença de reservatórios domésticos e silvestres, a possível presença de vetores e a história de casos humanos, estabelecendo, assim, a cadeia epidemiológica da doença.

- O nível de conhecimento acerca da doença foi razoável nas três áreas, pois parte dos entrevistados possuem algumas noções básicas em relação aos aspectos epidemiológicos (transmissão, vetores, reservatórios) e clínicos. Entretanto, os entrevistados das três localidades demonstraram ter pouco conhecimento sobre aspectos preventivos e terapêuticos.
- Para um melhor controle de doenças endêmicas como a LV, torna-se imprescindível que sejam criadas oportunidades para que a população possa ampliar seus conhecimentos e reduzir o risco de exposição as mesmas, sendo necessário:

1) Que os órgãos responsáveis implementem programas profiláticos, como educação em saúde, melhoria de habitações e saneamento básico, priorizando maior mobilização da população no sentido de despertar a consciência, sensibilizá-la e promover sua participação efetiva no combate à LV.

2) Capacitação e reciclagem dos profissionais de saúde, com o intuito de mantê-los aptos a informar corretamente a população sobre os vários aspectos (transmissão, prevenção e controle) do calazar, promovendo, assim, uma mudança comportamental da mesma em face de certos hábitos que propiciam a instalação da doença.

3) Implantação de postos médicos de atendimento nas áreas de maior risco, bem como de canis, para que a população possa referir os casos humanos e caninos suspeitos. 


\section{Agradecimentos}

À Fundação Nacional de Saúde/ Maranhão, na pessoa do Dr. Pedro Fernandes (Diretor do Departamento de Operações de Campo), pelo auxílio na execução do trabalho de campo; às profissionais Janaina T. Vieira e Silvana K. de Oliveira e aos estudantes Antônio Borba Júnior, Newlena Agostinho e Fábio Figueiredo, pela ajuda na coleta e digitação dos dados.

\section{Referências}

ALENCAR, J. E., 1983. Expansão do Calazar no Brasil. Ceará Médico, 5: 86-102.

ALVIM, M. C.; ALVIM, A. C.; ALVIM, M. A. B. \&VALE, J. J., 1986. Situação atual do calazar na ll ha de São Luís, Estado do Maranhão. Revista da Sociedade Brasileira de Medicina Tropical, 19(supl.):73.

COSTA, J. L.; VIANNA, G. L.; SALDANHA, A. R.; NASCIMENTO, M. D. S.; ALVIM, A. C.; BURATTINI, M. N \& SILVA, A. R., 1995. Leishmaniose visceral no Estado do Maranhão, Brasil. A evolução de uma epidemia. Cadernos de Saúde Pública, 11:321-324.

ESTESO, S. C., 1984. Educación popular - punto débil en la lucha contra la enfermedad de Chagas. Revista da Faculdade de Ciências Médicas da Universidade Nacional deCórdoba, 42:14-17.

GARCIA-ZAPATA, M. T. A., 1990. Controle da Doença de Chagas com Inseticidas e Partici pação Comunitária em Mambaí - GO. Tese de Doutorado, Belo Horizonte: Faculdade de Medicina da Universidade Federal de Minas Gerais.

GENARO, O.; SILVA, A. F.; MICHALICK, M. S. M.; COSTA, C. A; MAYRINK, W. \& DIAS, M., 1995. Leishmaniose visceral americana. In: Parasitologia Humana (D. P. Neves, A. L. Melo, O. Genaro \& P. M. Linardi, orgs.), pp. 55-72. São Paulo: Ed. Atheneu.

GONÇALVES, A. J. R.; ROZEMBAUM, R.; CUNHA, R. Q.; MENEZES, J. A.; VIEIRA FILHO, E. C. \& CARVALHO, F. G., 1986. Calazar: relato de três pacientes adultos internados no HSE-INAM PS (RJ): considerações sobre esta endemia de grande importância em nosso território. Arquivos Brasileiros de Medicina, 60:369-376.

MAGALHÃES, H. M. T. V.; COSTA, J. M. L.; COSTA, R. M.; FRANÇA, F.; VALE, K.; MARSDEN, P. \& MAGALHÃES, A., 1990. Mudança do componente cognitivo da atitude de uma população de região endêmica do Sul da Bahia, diante da leishmaniose tegumentar. Revista da Sociedade Brasileira de Medicina Tropical, 23:49-52.

MARZOCHI, K. B. F.; CALDERON, J. M. L. \& BONFIM, M. L., 1986. Calazar no Brasil: problema em ascensão. Ars Curandi, 19:139-44.

MS (Ministério da Saúde), 1996. Controle, Diagnóstico e Tratamento da LeishmanioseVisceral. Normas técnicas. Brasília: MS.

NASCIMENTO, M. D. S.; COSTA, J. M. L.; FIORI, B. I. P.; VIANA, G. M.; FILHO, M. S. G.; ALVIM, A. C.;
BASTOS, O.; NAKATANI, M.; REED, S.; BADARÓ, R.; SILVA, A. R. \& BURATTINI, M., 1996. Aspectos epidemiológicos determinantes na manutenção da leishmaniose visceral no Estado do Maranhão - Brasil. Revista da Sociedade Brasileira de Medicina Tropical, 29:233-240.

NASCIMENTO, M. D. S., 1996. Epidemiologia da LeishmanioseVisceral na Ilha de São Luís, Maranhão - Brasil: Análise da Dinâmica de Transmissão e dos Fatores de Risco Relacionados ao Desenvolvimento da Doença. Tese de Doutorado, São Paulo: Faculdade de Medicina da Universidade Federal de São Paulo.

NETTO, E. M.; TADA, M. S.; GOLIGHTLY, L.; KALTER, D.; IAGO, E.; BARRETO, A. \& MARSDEN, P., 1985. Conceitos de uma população a respeito da leishmaniose mucocutânea em uma área endêmica. Revista da Sociedade Brasileira de Medicina Tropical, 18:33-37.

ROCHA, F. A.; OLIVEIRA, M. F.; NOGUEIRA, N. A. P. \& FREITAS, C. E. J., 1991. Estudo epidemiológico dos casos de leishmaniose visceral (calazar) registrados no Hospital São José, de 1980 a 1990 em Fortaleza - Ceará. Revista Brasileira de Análises Clínicas, 23:87-92.

SHERLOK, I. A.; MIRANDA, J. C.; SADIGURSKY, M. \& GRIMALDI Jr, G., 1984. Natural infection of the opossun Didelphis albiventris (Marsupialia, Didelphidae) with Leishmania donovani in Brazil. Memórias do Instituto Oswaldo Cruz, 79:511.

TRAVI, B. L.; JARAMILO, C.; MONTOYA, J.; SEGURA, I.; ZEA, A.; GONÇALVES, A. \& VELEZ, I. D., 1994. Didel phis marsupialis, an important reservoir of Tripanosoma (Schizotrypanum) cruzi and Leishmania (Leishmania) chagasi in Colombia. American Journal of Tropical Medicine and Hygiene, 50:557-565.

VÁZQUEZ, M. L.; KROEGER, A.; LIPOWSKY, R. \& ALZATE, A., 1991. Conceptos populares sobre la leishmaniasis cutanea en Colombia y su aplicabilidad en programas de control. Boletín de la Oficina Sanitaria Panamericana, 110:402-415.

VIEIRA, J. B. F., 1987. O controle das leishmanioses no Brasil. Hiléia Médica, 8:13-35.

WHO (World Health Organization), 1990. Control of theleishmaniasis. Technical Report Series. Genebra:WHO. 